\title{
Cognizance of Congenital Cytomegalovirus
}

\author{
K. Deepa \\ Research Scholar \\ Rathinavel Subramaniam College of Arts and \\ Science \\ Sulur, Coimbatore \\ Tamilnadu, India
}

\author{
S. Suganya, $\mathrm{PhD}$ \\ Associate Professor \\ Rathinavel Subramaniam College of Arts and \\ Science \\ Sulur, Coimbatore \\ Tamilnadu, India
}

\begin{abstract}
Cytomegalovirus infection(CMV) has become the most common problems around the globe that infects all the people of all ages. Once the CMV is in the human body it stays for there for life and can reactivate. There are no symptoms or signs those who have got affected. CMV can cause serious hazards for the people who have weak immune system and unborn babies( Congenital cytomegalovirus). CMV is a common viral infection, especially among young children. Congenital CMV occurs when the infection is passed across the placenta from a pregnant woman to her developing baby. This can happen when a pregnant woman is infected with CMV for the first time, or is infected with CMV again during pregnancy Some babies with congenital CMV infection show signs of disability at birth, while others are born healthy. Some babies with signs of congenital CMV infection at birth may have long-term health problems. This paper reveals the review of the importance of congenital CMV virus among the common people.
\end{abstract}

\section{Keywords}

Congenital Cytomegalovirus; Symptoms; CMV;

\section{INTRODUCTION}

Cytomegalovirus (CMV) is a common virus in the herpes virus family. Fifty per cent people have been infected by young adulthood and up to 85 per cent by 40 years of age[14]. Peaks of infection occur in children less than 2 years age, and during adolescence. Once a person becomes infected, the virus remains alive but usually inactive (dormant) within that person's body for life. It is rare for a person to get symptoms after the initial infection unless their immune system is weakened by severe illness and treatments (e.g. for cancer).Reactivation can occur during pregnancy in women who have had infection previously, with a very small risk of transmission of CMV to the unborn baby[1][12]. Humans are the only source of CMV. The virus is found in urine, saliva, nasal mucous, breast milk, vaginal secretions and semen of infected people. The risk of transmission from children born with disability due to CMV infection is no greater than that from children who have CMV infection without symptoms.

CMV is spread through: close contact with a person excreting the virus in their saliva, nasal mucous, urine or other body fluid,handling children's toys that have saliva or mucous on them, or handling contaminated items like dirty tissues or soiled nappies then touching the eyes, nose or mouth without first washing hands, from mother to her unborn child as a result of maternal infection during pregnancy,from mother to her unborn child as a result of virus reactivation during pregnancy[12].A person who has been infected with CMV will develop antibodies in their blood that indicate infection has occurred, either recently, or in the past. These antibodies stay in the body for the rest of that person's life. Other tests, that detect the virus, are used to determine if a person has an active CMV infection.Congenital CMV is kept going by the lack of awareness, inaccessibility of an effective vaccine and efficient therapeutictreatments. However, the infection in pregnant women and subsequently, congenital infection can be markedly reduced with the use of knowledge about the nature of the virus and its ways of transmission[6].An immunoglobulin test measures the level of certain immunoglobulins, or antibodies in the blood[9][21][24]. Antibodies are the proteins made by the immune system to fight antigens such as bacteria,viruses and toxins the five subclasses of antibodies are shown below in Figure 1 .

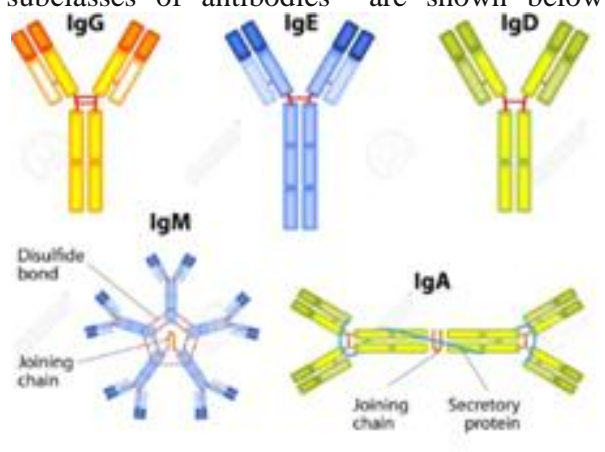

Figure 1: Antibody Classification

The body makes different immunoglobulins to combat different antigens[22]. For example, the antibody for chickenpox isn't the same as the antibody for mononucleosis. Sometimes, the body may even mistakenly make antibodies against itself, treating healthy organs and tissues like foreign invaders. This is called an autoimmune disease.

The five subclasses of antibodies are:

1. Immunoglobulin A $(\operatorname{IgA})$, which is found in high concentrations in the mucous membranes, particularly those lining the respiratory passages and gastrointestinal tract, as well as in saliva and tears.

2. Immunoglobulin $\mathbf{G}$ (IgG), the most abundant type of antibody, is found in all body fluids and protects against bacterial and viral infections.

3. Immunoglobulin M (IgM), which is found mainly in the blood and lymph fluid, is the first antibody to be made by the body to fight a new infection.

4. Immunoglobulin $\mathbf{E}$ (IgE), which is associated mainly with allergic reactions (when the immune system overreacts to environmental antigens such as pollen or pet dander). It is found in the lungs, skin, and mucous membranes. 
5. Immunoglobulin D (IgD), which exists in small amounts in the blood, is the least understood antibody.

$\operatorname{IgA}, \operatorname{IgG}$, and $\operatorname{IgM}$ are often measured together. That way, they can give doctors important information about immune system functioning, especially relating to infection or autoimmune disease. Hearing problems are the most common children' s sensory deficit and sensorineural hearing loss reveals to be the most common congenital kind of hypoacusia. The congenital Cytomegalovirus infection (CMV infection) has been classified as the main not genetic cause of sensorineural hearing loss among all possible causes of pediatric hearing reduction[13].

\section{CAUSES FOR CMV}

Cytomegalovirus (CMV) is a common virus that can infect almost anyone. Once infected, your body retains the virus for life. Most people don't know they have CMV because it rarely causes problems in healthy people.

\subsection{Intrauterine}

Intrauterine infection is thought to follow maternal viraemia and placental infection. Research into intrauterine infection has been hampered by the lack of maternal symptoms. Intrauterine transmission only occurs in $1 / 3$ rd of women who experience primary infection during pregnancy. Congenital infection can also result from recurrent maternal infection. Intrauterine transmission can occur at any time during pregnancy. (reinfection or reactivation)[7][8]. This may be surprising in view of the fact that large amounts of anti-CMV antibodies may be in circulation. However there may be other routes available for transmission such as the introduction of infected spermatozoa into the uterus or the reactivation of CMV that is already present in the endometrium of the uterus. However, such routes are purely speculative at the present.

\subsection{Perinatal}

Perinatal infection is acquired mainly through 2 sites - (i) Infected genital secretions, or (ii) Breast milk[10]. Once ingested, CMV usually gains access to the neonate by infecting the salivary glands. Overall, $2-10 \%$ of infants are infected by the age of 6 months worldwide. Perinatal infection is thought to be 10 times more common than congenital infection.[8]

\subsection{Postnatal}

The usual absence of symptoms associated with CMV infection made it difficult to ascertain routes of transmission. The following are the probable routes of transmission.

\subsubsection{Saliva}

Saliva is probably the main route through which the virus is transmitted postnatally. This is likely to be the route through which the virus is transmitted amongst young children.

\subsubsection{Sexual Transmission}

Sexual transmission is possible but not proven beyond doubt. CMV is found in semen and in the cervix. However oral-oral contact frequently occurs before intercourse which may well be the route through which the virus has been transmitted after intimate contact. However, susceptible homosexuals run a particularly high risk of being infected. Rectal intercourse seems to be a risk factor.

\subsubsection{Blood Transfusion}

In the early 1960s, a postperfusion syndrome was recognized in open heart surgery patients who received large quantities of blood which were contaminated with CMV. However transmission of CMV by blood is clearly a rare event as only 3 - 5\% of blood taken from seropositive donors leads to infection of seronegative recipients. It has not been possible to determine which donors have a high risk of transmitting the virus. It is possible that CMV persists in a latent state in blood leucocytes, and CMV is occasionally reactivated on transfusion[4].

\subsubsection{Organ Transplantation}

Patients undergoing renal transplantation are particularly at risk. Seronegative recipients have a $5 \%$ chance of acquiring primary infection from seronegative donors compared to a chance of $70-80 \%$ of acquiring primary infection from seropositive donors. It seems that CMV is transmitted via infected cells in the donor kidney.It is also possible to transmit CMV in other types of organ transplantation such as the bone marrow, heart, heart and lung, and the liver. Although in the case of the liver, 50 - 100 units of blood is commonly given which carries a far greater risk of transmission. Often, particularly in the case of bone marrow transplantation, the virus causing disease after the transplantation came from the recipient rather than the donor. Also the serological evidence for the transmission of $\mathrm{CMV}$ in the case for bone marrow transplantation is not as strong as that for renal transplantation.

Biomolecules and tissues are usually paramagnetic or diamagnetic materials, except blood where iron is present in erythrocytes (red blood cells). We investigate the presence of viral infection in blood plasma, which does not contain erythrocytes, and which is not ferromagnetic. The most common viruses that infect over $90 \%$ of world population are the Epstein-Barr virus (EBV) and cytomegalovirus (CMV), belonging to the herpes virus family[20].

The manifestations of this infections are various, from persistent latent asymptomatic infection in immunocompetent population to development of wide spectrum of clinical manifestations that range from transient infections to aggressive malignancies in some immunocompromised patients.

\section{DIAGNOSIS OF CMV}

Testing for CMV is not routinely recommended for all women during pregnancy or for newborn babies. CMV testing is currently recommended for pregnant women who develop an acute viral illness or when ultrasound reveals a fetal abnormality. However, pregnant women and women planning a pregnancy may wish to discuss CMV testing with their doctor, particularly if they work in high risk settings (e.g. in child care centers) or have very young children at home.

Infants born to mothers diagnosed with a primary CMV infection during pregnancy should be tested for congenital CMV infection[15]. Babies who do not have a normal hearing screening test at birth SWISH-(State Wide Infant Screening Hearing Program) can also be tested for congenital CMV, as hearing loss is the most common sign of congenital CMV. However, some infants with congenital CMV infection who appear healthy at birth develop hearing or vision loss over time. For this reason babies known to be infected should have their hearing and vision assessed regularly. The potential infant disability are shown in the Figure 2. 


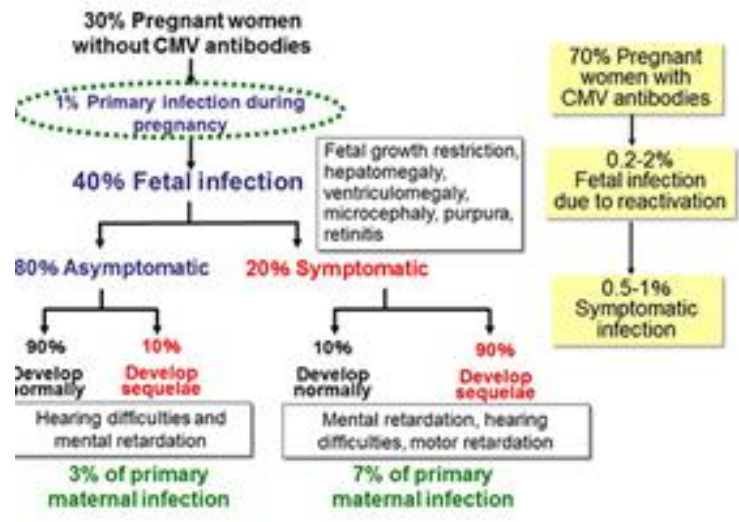

\section{Figure 2: Potential infant disability from Maternal CMV infection.}

It is well known that primary infections in the mother have a much greater clinical impact on the fetus than reactivated infections or exogenous reinfections[5]. Prevention is difficult because the virus is ubiquitous and infection is common.The anti-CMV IgG avidity test is currently the most reliable[11] . Congenital CMV is kept going by the lack of awareness,inaccessibility of an effective vaccine and efficient therapeutic treatments. However, the infection in pregnant women and subsequently, congenital infection can be markedly reduced with the use of knowledge about the nature of the virus and its ways of transmission.Serum IgM to CMV can be revealed by a variety of different tests; the most widely used is the enzyme-linked immunosorbent assay (ELISA) Serologic tests that detect CMV antibodies (IgM and IgG antibody to CMV) are widely available from commercial laboratories. The enzyme-linked immunosorbent assay (ELISA) is the most common serologic test for measuring antibody to CMV.A positive test for CMV IgG indicates that a person was infected with CMV at some time during their life, but does not indicate when a person was infected.Measurement of CMV IgG in paired samples taken one to three months apart can be used to diagnose primary infection; seroconversion $\left(1^{\text {st }}\right.$ sample IgG negative, $2^{\text {nd }}$ sample IgG positive) is clear evidence for recent primary infection. The presence of CMV IgM cannot be used by itself to diagnose primary CMV infection because $\operatorname{IgM}$ can also be present during secondary CMV infection. IgM positive results in combination with low $\operatorname{IgG}$ avidity results are considered reliable evidence for primary infection, with limitations of avidity sting described below.

IgG avidity testing may provide useful information regarding timing of infection. IgG antibodies produced following primary CMV infection have low avidity (low binding strength)[16][17]. Two to four months following infection, IgG antibodies mature to high-avidity (high binding strength). Therefore, avidity assays can be used to assess low avidity (which indicates recent infection) versus high avidity (past infection). However, not all avidity assays have been validated and, therefore, should be interpreted with caution.

The standard laboratory test for diagnosing congenital CMV infection is polymerase chain reaction (PCR) on saliva, with urine usually collected and tested for confirmation. The reason for the confirmatory test on urine is that most CMV seropositive mothers shed CMV virus in their breast milk. Polymerase chain reaction (PCR) amplification is being used more frequently for the diagnosis of viral infections because of its enhanced sensitivity and rapid turnaround[2].
Specific steps for appropriate collection of saliva samples from a baby are as follows:

1. Collect a saliva specimen more than one hour after breastfeeding and within three weeks of birth, because detection of CMV after three weeks could be the result of post-partum infection.

2. Insert a sterile cotton or polyester swab into the baby's mouth between the gum and cheek and swirl for several seconds.

3. Remove the swab and place into a buffer formulated for PCR diagnostic testing (several are available). If CMV is present, it will leach from swab to the liquid.

The liquid is processed according to manufacturer's instructions, and PCR testing is performed according to the protocol in the laboratory. Specific procedures and interpretation of tests vary according to the laboratory.Currently, testing of newborns for CMV is not routinely performed, though some states perform targeted CMV testing of newborns who fail the hearing screening. CDC is currently studying whether dried blood spots (DBS)[3], which are already collected on almost all newborns, can identify the majority of children most likely to suffer long-term health problems from congenital CMV.

Cytomegalovirus (CMV) infection continues to be a major problem for immunocompromised patients. Detection of viral antigens in leukocytes (antigenemia assay) is widely used for the diagnosis of CMV infection and for guiding antiviral therapy. The antigenemia technique, contingent upon the manual microscopic analysis of rare cells, is a laborious task that is subject to human error[19].The quantitative polymerase chain reaction (PCR) assay for CMV DNA and the antigenemia assay for the lower matrix phosphoprotein (pp65) CMV antigen are the two most widely used technologies for detecting CMV infection and monitoring patients' virologic response to therapy.

\section{4. TREATMENT FOR CMV}

There is no licensed vaccine for CMV, and while candidate vaccines are progressing through clinical trials, a vaccine for use in routine clinical practice remains a distant prospect[18]. An alternative strategy to reduce the risk of infection is behavior modification in order to minimize CMV infection during pregnancy. Simple hygiene-based measures that have been shown to reduce the risk of CMV acquisition include hand washing after contact with urine or saliva, and avoiding sharing utensils, drinks or food with young children[25].

\section{CONCLUSION}

Cytomegalovirus infection during pregnancy creates more complications for the fetus in the womb, the detection of virus is done through medical diagnosis. Prevention can be done based upon hygienic measures taken by all group of people to get rid of virus. To have a better clarity of the structure of the antibodies digital image can also be implemented through techniques to identify patterns and segmentation of images. Image Segmentation provides a way to detect the virus in advanced technology to prevent from various infections at the early stage.

\section{REFERENCES}

[1] Britt W.Cytomegalovirus. In:Remington JS,Klein JO,Wilson CB,Baker CJ,eds.'Infectious diseases of the fetus and newborn infant, " $7^{\text {th }}$ ed.Philadelphia:W.B.Saunders Company, 2011:704-53

[2] Boppana SB, Ross SA, Shimamura M, et al. Saliva 
"Polymerase-chainreactionassay for cytomegalovirus screening in newborns". N Engl J Med 2011; 364:21118 .

[3] Boppana SB, Ross SA, Novak Z, et al. " Dried blood spot real-time polymerasechain reaction assays to screen newborns for congenital cytomegalovirus".

[4] . Bode'us M, Hubinont C, Goubau P." Increased risk of cytomegalovirus transmission in utero during late gestation". Obstet Gynecol 1999; 93:658-660.

[5] Revello MG, Zavattoni M, Furione M, Fabbri E, Gerna G. econceptional "Primary human cytomegalovirus infection and risk of congenital infection". J Infect Dis 2006; 193: 783-787.

[6] Kenneson A, Cannon MJ." Review and meta-analysis of the epidemiology of congenital cytomegalovirus (CMV) infection." Rev Med Virol 2007; 17: 253-276.

[7] . Lazzarotto T, Gabrielli L, Baccolini F et al. "Prenatal diagnosis of congenital cytomegalovirus (CMV) infection and outcome in 598 pregnant women undergoing a primary CMV infection”. OR\#10.2. In Abstracts of the 12th International CMV/BetaHerpesvirus Workshop, May 10-14 2009, Boston-USA

[8] de Vries JJ, van der Eijk AA, Wolthers KC, et al. "Realtime PCR versusviral culture on urine as a gold standard in the diagnosis of congenital cytomegalovirus infection”. J Clin Virol 2012; 53:167-70

[9] Nigro G, Adler SP, La Torre R, Best AM; “Congenital Collaborating Group. Passive immunization during pregnancy for congenital cytomegalovirus infection". N Engl J Med. 2005;353:1350-62.

[10] Yasuda A, Kimura H, Hayakawa M, et al. “ Evaluation of cytomegalovirus infections transmitted via breast milk in preterm infants with a real-time polymerase chain reaction assay”. Pediatrics 2003; 111:1333-6.

[11] Revello M, Genini E, Gorini G et al. "Comparative evaluationof eight commercial human cytomegalovirus IgG avidityassays”. J Clin Virol 2010; 48: 255-25

[12] Yinon Y, Farine D, Yudin M et al. "Cytomegalovirus infection in pregnancy". J Obstet Gynaecol Can 2010; 32: $348-354$

[13] Coll O, Benoist G, Ville $Y$ et al. "Guidelines on CMVcongenital infection". J Perinat Med 2009; 37: 433445 .

[14] . Rawlinson W, Scott G. "Cytomegalovirus. A common virus causing serious disease". Aust Fam Physician
2003; 32: 789-793.

[15] Wang C, Zhang X, Bialek S, Cannon M." Attribution ofcongenital cytomegalovirus infection to primary versus non-primary maternal infection”. Clin Infect Dis 2011; 52: e11-e13.

[16] . Liliane Grangeot-Keros Marie Jeanne Mayaux Pierre Lebon François Freymuth Geneviève Eugene René Stricker Elisabeth Dussaix "Value of Cytomegalovirus (CMV) IgG Avidity Index for the Diagnosis of Primary CMV Infection in Pregnant Women "The Journal of Infectious Diseases, Volume 175, Issue 4, 1 April 1997, Pages 944-946..

[17] Cytomegalovirus Viral Immunology “ Maternal IgG Avidity and IgM Detected by Blot as Diagnostic Tools to Identify Pregnant Women at Risk of Transmitting" January 2009,13(1):137-141.

[18] Rajiv Khanna . "Immune monitoring of infectious complications in transplant patients: Animportant step towards improved clinical management" JCM Accepted Manuscript Posted Online 17 January 2018

[19] Andras Ladanyi,1* Andrew C. Sher,1 Anna Herlitz,1 Danielle E. Bergsrud,1 Stine-Kathrein Kraeft,1 Jane Kepros,1 Gizelda McDaid,1 David Ferguson,2 Marie L. Landry, 2 and Lan Bo Chen1"Automated Detection of Immunofluorescently Labeled Cytomegalovirus-Infected cells in Isolated Peripheral Blood Leukocytes Using Decision Tree Analysis" $7^{\text {th }}$ January 2004.

[20] M. Papic-Obradovica, D. Kojic $b$ and A.L. Matijab $a$ Clinic for Gynecology and Obstetrics "Narodni front", Kraljice Natalije 62, 11000 Belgrade, Serbia $b$ Department for Biomedical Engineering, Faculty of Mechanical Engineering, University of Belgrade Kraljice Marije 16, 11120 Belgrade 35, Serbia . Opto-Magnetic Method for Epstein — Barr Virus and "Cytomegalovirus Detection in Blood Plasma Samples"

[21] National CMV Foundation.

[22] Organization of Teratology Information Specialists (OTIS, 2017): Cytomegalovirus (CMV)

[23] Centers for Disease Control \& Prevention: "Cytomegalovirus (CMV) and Congenital CMV Infection".

[24] "IgM antibody: Structure, Properties, Functions and Clinical Significance" 4.83/5 (6) April 28, 2016 by Tankeshwar Acharya in Immunology

[25] Congenital Cytomegalovirus Infection:" Update on Treatment" Scientific Impact Paper No. 56 First published: 15 November 2017. 